\title{
Adsorption of Arsenic on MgAl Layered Double Hydroxide
}

\author{
Davor Kovačević, ${ }^{\text {a,* }}$ Branka Njegić Džakula, ${ }^{\mathrm{b}}$ Damir Hasenay, ${ }^{\mathrm{c}}$ Ivan Nemet, ${ }^{\mathrm{a}}$ \\ Sanda Rončević, ${ }^{a}$ Imre Dékány, ${ }^{\mathrm{d}}$ and Dimitris Petridis ${ }^{\mathrm{e}}$
}

${ }^{a}$ Department of Chemistry, Faculty of Science, University of Zagreb, Horvatovac 102a, HR-10000 Zagreb, Croatia

${ }^{\mathrm{b}}$ Ruđer Bošković Institute, Bijenička cesta 54, HR-10000 Zagreb, Croatia

${ }^{\mathrm{c}}$ Department of Information Sciences, Faculty of Humanities and Social Sciences, University of Osijek,

L. Jägera 9, HR-31000 Osijek, Croatia

${ }^{\mathrm{d}}$ Department of Physical Chemistry and Materials Sciences, University of Szeged,

Aradi vt 1, H-6720 Szeged, Hungary

'Institute of Materials Science, NCSR “Demokritos", Agia Paraskevi 15310, Athens, Greece

\begin{abstract}
Groundwater in the Eastern Croatia, as well in the South-eastern Hungary, contains relatively high concentrations of arsenic that can cause chronic toxicity to humans. Therefore, the aim to find an effective composite adsorbent that can be applied for arsenic water remediation by introducing it in the groundwater treatment is very important. The presented results were obtained using layered double hydroxide (LDH) as a sorbing system. MgAl LDH samples with a Mg:Al molar ratio of 2:1 were synthesized. Adsorption of arsenic anions from groundwater samples from Eastern Croatia, as well as adsorption of model aquatic arsenic sample solutions, on MgAl layered double hydroxide was investigated. Inductively coupled plasma atomic emission spectrometry (ICP-AES) was used for determination of arsenic concentration after adsorption. It was shown that in both cases the adsorption process could be interpreted in terms of Kroeker adsorption isotherm regardless to the presence of other ions in the groundwater. Additionally, the influence of phosphate concentration on adsorption of model arsenic samples was examined and it was shown that (at least in examined range of arsenic and phosphate concentration) there is no significant influence of phosphate on adsorption of arsenic. (doi: 10.5562/cca2283)
\end{abstract}

Keywords: arsenic, groundwater, MgAl layered double hydroxide, ICP-AES, Kroeker isotherm

\section{INTRODUCTION}

Large populations of world receive potable water with elevated levels of arsenic compounds. According to the World Health Organization ${ }^{1}$ mass concentration of arsenic in the potable water should be lower than $10 \mu \mathrm{g} \mathrm{dm}{ }^{-3}$. Arsenic concentrations higher than that have been reported in water supplies throughout the world, e.g. Bangladesh, Argentina or United States. ${ }^{2-6}$ Groundwater in the eastern part of Croatia (Osijek and Vinkovci regions) also contains relatively high concentrations of arsenic due to the presence of arsenic from natural geological sources ${ }^{7,8}$ This element is also the number one pollutant of geological origin in Hungarian groundwaters. ${ }^{9}$ Levels of arsenic exceed the above mentioned limiting value at 400 Hungarian settlements (with approximately 1.5 million inhabitants), especially at the Pannonian Plain and South Transdanubia, along the Croatian border. According to the World Health Organ- ization, regular consumption of high dosages of arsenic may cause hyper- and hypopigmentation, peripheral vascular disease or cancer. ${ }^{1}$ It is thus obvious that safe and effective water treatment technologies are needed for arsenic removal from groundwater.

In natural waters inorganic arsenic is usually found in the form of arsenite $\left(\mathrm{As}^{\mathrm{III}} \mathrm{O}_{3}{ }^{3-}\right)$ and/or arsenate $\left(\mathrm{As}^{\mathrm{V}} \mathrm{O}_{4}{ }^{3-}\right)$ depending on the oxidative or reductive environment. ${ }^{10} \mathrm{At}$ the $\mathrm{pH}$ of drinking water (normally ranging from 6.5 to 8.5) the dominant arsenite species is $\mathrm{H}_{3} \mathrm{AsO}_{3}(\mathrm{p} K=9.2)$, whereas arsenate is present as $\mathrm{H}_{2} \mathrm{AsO}_{4}^{-}$and $\mathrm{HAsO}_{4}{ }^{2-}, \mathrm{p} K_{1}=2.3$ and $\mathrm{p} K_{2}=7.0$. Both arsenite and arsenate may be subjected to chemical and/or microbiologically mediated redox and methylation reactions in water producing the highly toxic methyl derivatives. ${ }^{11}$ In such waters the interaction of soluble arsenic compounds with ground hydrous oxide surfaces is of paramount importance because the As(III) and $\mathrm{As}(\mathrm{V})$ compounds are effectively adsorbed by the

\footnotetext{
* Author to whom correspondence should be addressed. (E-mail: davor.kovacevic@chem.pmf.hr)
} 
oxide network. For these reasons conventional approaches for the arsenic removal include coagulation, flocculation and filtration processes with ferric or aluminium salts. At $\mathrm{pH}$ values of solution that are lower than the isoelectric point of the surface oxide (e.g. $\mathrm{pH}=$ 8 for $\left.\mathrm{Fe}(\mathrm{OH})_{3}\right)$ the surfaces are positively charged $\left[\mathrm{S}-\mathrm{OH}_{2}{ }^{+}\right]$, whereas at $\mathrm{pH}>8$ they are negatively charged $\left[\mathrm{S}-\mathrm{O}^{-}\right]$. Accordingly, at the $\mathrm{pH}$ of drinking water $\mathrm{As}(\mathrm{III})$ and $\mathrm{As}(\mathrm{V})$ are electrostatically bound to the oxide surfaces and thus a significant adsorption is expected, with low As concentrations in water. At higher $\mathrm{pH}$ values, ligand exchange reactions lead to the formation of surface $[\mathrm{FeO}]-\mathrm{Fe}-\mathrm{O}-\mathrm{AsO}^{n-}$ species. The net result is that the colloidal hydrous iron oxides or oxyhydroxides are excellent agents for the removal of soluble arsenic compounds from water reservoirs.

In our study as the adsorbing system layered double hydroxides (LDHs) are used. The general formula for LDHs is $\left(\left[\mathrm{M}_{1-x}{ }^{2+} \mathrm{M}_{x}{ }^{3+}(\mathrm{OH})_{2}\right] \mathrm{A}^{n-}\right)_{x / n} \cdot y \mathrm{H}_{2} \mathrm{O}$, where $\mathrm{M}^{2+}$ and $\mathrm{M}^{3+}$ are metal ions and $\mathrm{A}^{n-}$ stands for anions exchangeable between octahedral sheets $\left(\mathrm{Cl}^{-}, \mathrm{NO}_{3}^{-}\right.$, $\left.\mathrm{CO}_{3}{ }^{2-}, \mathrm{SO}_{4}{ }^{2-}\right)$. These characteristics result in the unique properties of layered solids. Synthetic LDHs are good adsorbents and catalyst supports with large interlayer surfaces. The layers of LDH can be pillared with large organic and inorganic anions, which increases their basal spacing and these materials therefore have large specific surface areas and porous volumes. ${ }^{12-14}$ LDHs are also excellent anion exchangers, which can therefore be utilized, together with negatively charged polymers, as a hybrid layer component for the preparation of thin nanohybrid films. ${ }^{15-17}$ They are good catalysts because divalent and trivalent metal cations can be incorporated into the octahedral lattice. The LDHs synthesized are converted, for optimal catalytical activity, to mixed metal oxides at temperatures over $400{ }^{\circ} \mathrm{C}$ by calcination. ${ }^{18-20}$ Nowadays LDHs are also used as supports in bionanocomposites for medical applications. ${ }^{21,22}$ Therefore we decided to investigate the adsorption of arsenic from groundwater samples from Eastern Croatia on $\mathrm{MgAl}$ layered double hydroxide and to compare it with the adsorption of model arsenic samples on the same substrate. Additionally, the aim of the study was to examine the influence of phosphate concentration on adsorption of commercially obtained arsenic samples.

\section{EXPERIMENTAL}

\section{Materials and Methods}

\section{Materials}

Magnesium nitrate hexahydrate $\left(\mathrm{Mg}\left(\mathrm{NO}_{3}\right)_{2} \cdot 6 \mathrm{H}_{2} \mathrm{O}\right)$, puriss., Fluka, aluminium nitrate nonahydrate $\left(\mathrm{Al}\left(\mathrm{NO}_{3}\right)_{3}\right.$ - $\left.9 \mathrm{H}_{2} \mathrm{O}\right)$, puriss., sodium hydroxide $(\mathrm{NaOH})$, analytical grade, and sodium nitrate $\left(\mathrm{NaNO}_{3}\right)$, puriss., Reanal
Hungary, were used to prepare $\mathrm{MgAl}$ layered double hydroxide.

For adsorption measurements aqueous solution of disodium hydrogen arsenate heptahydrate $\left(\mathrm{Na}_{2} \mathrm{HAsO}_{4}\right.$. $7 \mathrm{H}_{2} \mathrm{O}$ ), Sigma was used. All solutions were prepared using deionised water $\left(\kappa<3 \mu \mathrm{S} \mathrm{cm} \mathrm{cm}^{-1}\right)$. Chemicals: $\mathrm{Na}_{2} \mathrm{HPO}_{4} \cdot 2 \mathrm{H}_{2} \mathrm{O}, \mathrm{Na}_{2} \mathrm{HAsO}_{4} \cdot 7 \mathrm{H}_{2} \mathrm{O}$ and $\mathrm{NaCl}$, used in these experiments were of analytical purity grade. Groundwater samples were obtained from 4 different wells around Osijek in Eastern Slavonia, Croatia (denoted as B2, B8, B10 and B13).

\section{Preparation and Characterization of MgAl Layered Double Hydroxide}

Magnesium nitrate hexahydrate and aluminium nitrate nonahydrate were dissolved in boiled distilled water at a $\mathrm{Mg}$ :Al molar ratio of 2:1 (solution 1); $25 \mathrm{~g}$ of sodium hydroxide and $20 \mathrm{~g}$ of sodium nitrate were also dissolved in boiled distilled water (solution 2). Under vigorous stirring, solution 1 was added dropwise to solution 2 in $3 \mathrm{~min}$. The samples were synthesized in nitrate form at $\mathrm{pH}$ values of 9.1, 9.6, 11.2 and 13.1. The $\mathrm{pH}$ of the suspension was adjusted using $0.1 \mathrm{M} \mathrm{NaOH}$ and $0.1 \mathrm{M} \mathrm{HNO}_{3}$ and the slurry was stirred at $25{ }^{\circ} \mathrm{C}$ for 20 minutes. After ageing for $5 \mathrm{~min}$, the sediment was centrifuged, washed once with distilled water and centrifuged again; the product was then dried at $65^{\circ} \mathrm{C}$. Optimal synthesis of $\mathrm{LDH}$ is carried out at $40-60{ }^{\circ} \mathrm{C}$ in inert gas atmosphere, in a $\mathrm{CO}_{2}$-free solution. Our syntheses were carried out at room temperature and in air atmosphere without the exclusion of $\mathrm{CO}_{2}$ gas, because our aims were (i) efficient arsenate removal and (ii) production of a cheap adsorbent for industrial application. Due to increasing the $\mathrm{pH}$ of the synthesis medium, which results in increasing dissolution of atmospheric carbon dioxide, the nitrate/carbonate ratios of the LDHs obtained are 2.6, 1.8, 0.8 and 0.1 . In the experiments presented in this study only the sample with $\mathrm{NO}_{3}{ }^{-} / \mathrm{CO}_{3}{ }^{2-}$ ratio 0.1 was used.

To determine the crystalline structure X-ray diffraction (XRD) measurements were carried out on a Bruker D8 Advance $\left(\mathrm{Cu} \mathrm{K} \mathrm{K}_{\alpha}\right.$ radiation, $\left.40 \mathrm{kV}, 30 \mathrm{~mA}\right)$ diffractometer at the ambient temperature in the $2 \Theta$ range of $20-80^{\circ}$.

Specific surface areas were determined by a Micromeritic gas adsorption analyzes (Gemini type 2375) at $-196{ }^{\circ} \mathrm{C}$ in liquid nitrogen. The adsorption and desorption branches of the isotherms were determined. Prior to the measurements samples were preheated at $50{ }^{\circ} \mathrm{C}$ in vacuum ( 0.01 Torr). The adsorption isotherms were analyzed by the means of BET equation and $\mathrm{BJH}$ method.

The particle size of the prepared LDH was examined by a transmission electron microscopy (TEM) using a Philips CM-10 transmission electron microscope applying $100 \mathrm{kV}$ accelerating voltage. The morphology 
of the samples was characterized by Atomic Force Microscope Nanoscope III, Digital Instruments, USA, scanner with a piezo (scanning capability of $12.5 \mu \mathrm{m}$ in $x$ and $y$ direction and $3 \mu \mathrm{m}$ in $z$ direction). A tapping type tip made of silicon was used (Veeco Nanoprobe Tips RTESP model, $125 \mu \mathrm{m}$ length, $300 \mathrm{kHz}$ ) during measurements.

\section{Adsorption of Arsenic on Layered Double Hydroxides} Batch Adsorption Experiments

Adsorption of arsenic on LDH was studied at $25{ }^{\circ} \mathrm{C}$. Suspensions of LDH were prepared by the following procedure: LDH was weighed in the glass tubes which were then filled with arsenic solution. The arsenic samples were prepared by adding appropriate volume of stock solution of arsenic and then filled with $\mathrm{NaCl}$ aqueous solution $\left(c=0.02 \mathrm{~mol} \mathrm{dm}{ }^{-3}\right)$, up to $25 \mathrm{~cm}^{3}$, to keep the ionic strength constant. In order to investigate the influence of the phosphate, which is present in the groundwater samples, on the adsorption of the arsenic on LDH, appropriate volume of stock solution of phosphate was added. Mass concentration of the LDH in these suspensions varied from $0.25 \mathrm{~g} \mathrm{dm}^{-3}$ to $1.00 \mathrm{~g} \mathrm{dm}^{-3}$, arsenic concentration varied from $500 \mu \mathrm{g} \mathrm{dm}^{-3}$ to 4000 $\mu \mathrm{g} \mathrm{dm}^{-3}$, while phosphate concentration varied from 50 $\mu \mathrm{g} \mathrm{dm}^{-3}$ to $2000 \mu \mathrm{g} \mathrm{dm}^{-3}$. In the case of groundwater samples, LDH was weighed in the glass tubes which were then filled with arsenic solution groundwater samples. Concentrations of the arsenic in these samples were: $0.069 \mathrm{mg} \mathrm{dm}^{-3}, 0.120 \mathrm{mg} \mathrm{dm}^{-3}, 0.180 \mathrm{mg} \mathrm{dm}^{-3}$, $0.195 \mathrm{mg} \mathrm{dm}^{-3}$ and $0.300 \mathrm{mg} \mathrm{dm}^{-3}$, while mass concentration of $\mathrm{MgAl} \mathrm{LDH}$ in these suspensions varied from $0.25 \mathrm{~g} \mathrm{dm}^{-3}$ to $1.00 \mathrm{~g} \mathrm{dm}^{-3}$.

Prepared suspensions were constantly shaken for $30 \mathrm{~min}$. This period was chosen because the preliminary experiments showed that the constant (maximum) adsorbed mass was achieved after $30 \mathrm{~min}$. In order to determine the adsorbed amount of arsenic, suspensions were filtered and the equilibrium concentration of arsenic acid was determined by inductively coupled plasmaatomic emission spectrometry (ICP-AES). The adsorbed amount of arsenic was calculated by the equation

$$
n_{\mathrm{ads}}=\frac{V\left(c_{0}-c_{\mathrm{eq}}\right)}{m}
$$

where $V$ is the total volume of the aqueous solution in the glass tube, $c_{0}$ and $c_{\mathrm{eq}}$ are the initial and equilibrium arsenic concentrations, respectively, and $m$ is the mass of MgAl LDH adsorbent.

Determination of Arsenic Concentration Instrumentation A Teledyne Leeman Labs. (Hudson, NH, USA) Prodigy High Dispersion ICP system was used. The instrument is equipped with $40 \mathrm{MHz}$ "free-running" radiofrequency generator and echelle grating spectrometer with a large- format programmable array detector (L-PAD). Sample introduction system which consisted of a glass cylonic spray chamber and a glass concentric nebulizer was connected to a three channel peristaltic pump and reaction coil of hydride generator (HG, Leeman Labs. Inc.). The dual-view torch for observing both axial and radial position was used. The sample solution uptake rate was adjusted on $0.9 \mathrm{~cm}^{3} \mathrm{~min}^{-1}$. The r.f. power of $1.3 \mathrm{~kW}$, and flow rates of argon (coolant $18 \mathrm{dm}^{3} \mathrm{~min}^{-1}$, auxiliary $0.8 \mathrm{dm}^{3} \mathrm{~min}^{-1}$ ) were held constant in all measurements. Emission lines of arsenic (189.042 nm, $193.759 \mathrm{~nm})$ were selected from image on L-PAD detector as the most prominent lines without spectral and background interferences. Additional argon purging of spectrometer optics was switched on before and during signal acquisition. Integration time was adjusted to $15 \mathrm{~s}$ and signal acquisition was repeated three times throughout measurements.

\section{Procedures}

High-purity deionised water (18 M $\Omega \mathrm{cm}$, Milli-Q Element system, Millipore, USA) was used for the preparation of standard solutions and dilution of samples. Single element standard solutions of As $1000 \mathrm{mg} \mathrm{dm}^{-3}$ (Plasma Pure, Leeman Labs, Hudson, NH, USA) was used for the preparation of calibration standard solutions and control of plasma line positioning. For the determination of arsenic by HG-ICP-AES, a fresh solution of $\mathrm{NaBH}_{4}\left(\gamma=8 \mathrm{~g} \mathrm{dm}^{-3}, w \approx 0.8 \%\right)$ in $\mathrm{NaOH}(w=0.5 \%)$ was prepared. Calibration solutions of As were prepared in the range of $0.1-1.0 \mathrm{mg} \mathrm{dm}^{-3}$ by dilution to appropriate volume with hydrochloric acid solution (volume fraction, $\varphi=10 \%$, Kemika, Croatia). Calibration blank contained only aqueous solution of hydrochloric acid. In order to verify the accuracy of measurement procedure, the certified reference material of river water SLRS-4 (NRCC) was analysed under the same operating conditions as were applied for the samples.

The phosphate matrix effects were examined in the mode of Method of standard addition (MSA). It included aliquots of prepared samples in which a standard solution of arsenic was added. MSA solutions were diluted with hydrochloric acid solution. The final concentration range in MSA sample solutions was $0.1-0.5$ $\mathrm{mg} \mathrm{dm}{ }^{-3}$ of arsenic.

\section{RESULTS AND DISCUSSION}

\section{MgAl Layered Double Hydroxide}

The prepared MgAl LDH samples were characterized by various methods (Figures 1. and 2.). As a consequence of synthesis in air, at increasing $\mathrm{pH}$ values icreasingly higher amounts of carbonate anions are incorporated into the interlamellar space of LDH. Since the carbonate anion has a lower space requirement and is 

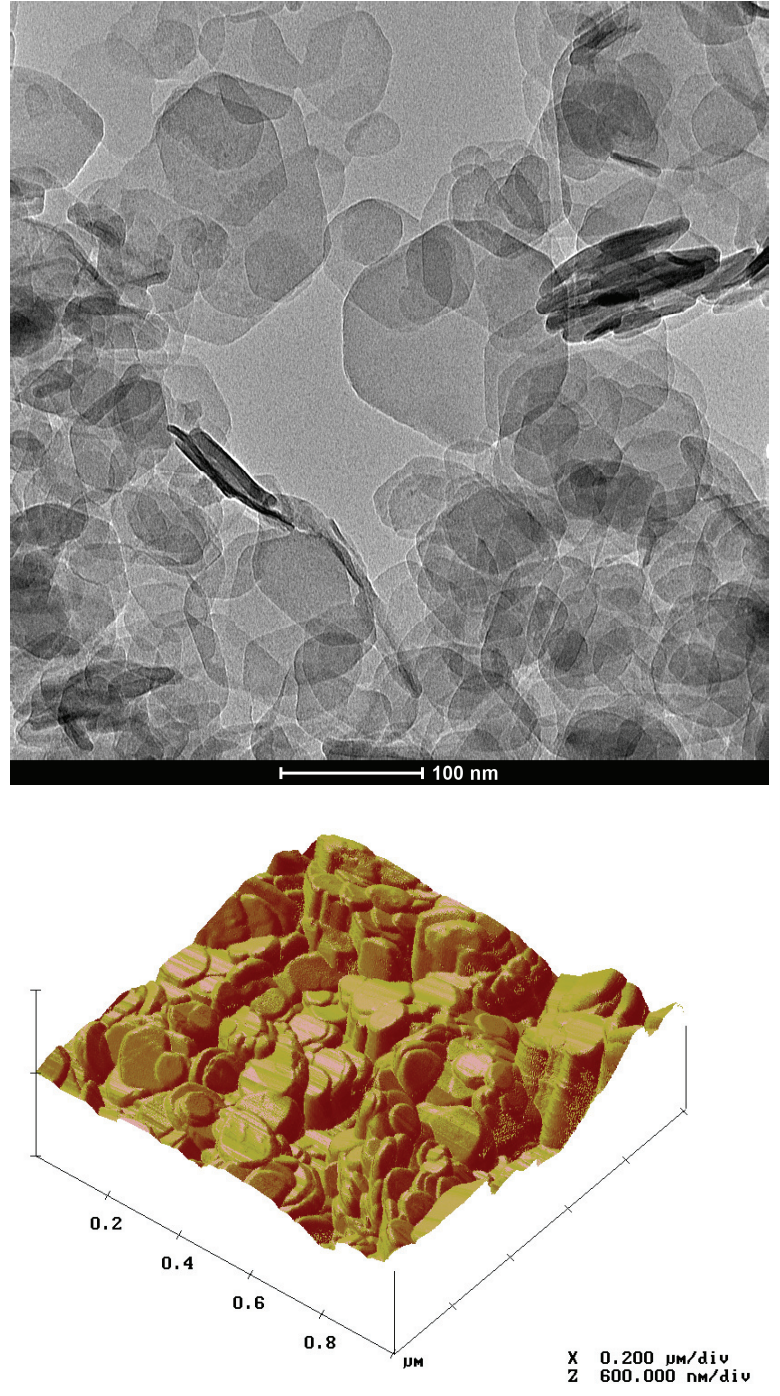

Figure 1. TEM image (a) and AFM image (b) of synthetic 2:1 $\mathrm{MgAl} \mathrm{LDH}$, with molar ratio $\mathrm{NO}_{3}{ }^{-} / \mathrm{CO}_{3}{ }^{2-}$ of 0.1 .

hydrated to a lesser extent than the nitrate anion, the basal spacing of LDH decreases with increasing carbonate content. For LDHs with $\mathrm{NO}_{3}{ }^{-} / \mathrm{CO}_{3}{ }^{2-}$ ratios of 0.1 and $0.8, \mathrm{~d}_{003}=0.769$ and $0.785 \mathrm{~nm}$ are in agreement with the data published for LDH in carbonate form (JCPDS 20-0658, 41-1425). The LDH particles were found to be nearly hexagonal in shape with diameters between 40 and $125 \mathrm{~nm}$. The diameter of $68 \%$ of the particles is $90-120 \mathrm{~nm}$ and no particle is smaller than $40 \mathrm{~nm}$ (Figure 1). The specific surface area of the investigated $\mathrm{MgAl} \mathrm{LDH}$ sample with molar ratio $\mathrm{NO}_{3}{ }^{-} / \mathrm{CO}_{3}{ }^{2-}$ of 0.1 was $47.4 \mathrm{~m}^{2} / \mathrm{g}$.

\section{Adsorption}

In order to analyse the adsorption behaviour of heavy metals or organic acids on metal oxides or on other substrates various adsorption isotherms could be used. $^{23,24}$ Since in the performed experiments the adsor-

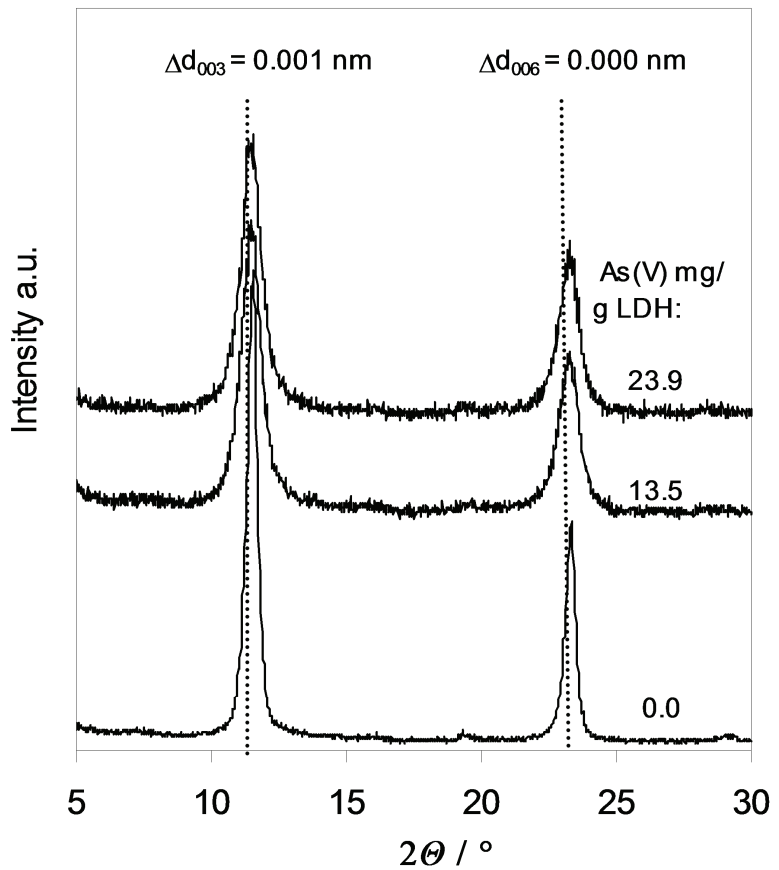

Figure 2. XRD patterns of the $\mathrm{MgAl} \mathrm{LDHs}$ with molar ratio $\mathrm{NO}_{3}{ }^{-} / \mathrm{CO}_{3}{ }^{2-}$ of 0.1 , before and after As adsorption.

bent concentration was varied, we decided to interpret the obtained results by means of the so called Kroeker isotherm which takes into account the mass concentration of the adsorbent. ${ }^{25,26}$ It was shown in the literature that many systems behave according to that empirical isotherm, although some cases were observed where that was not the case. ${ }^{26}$ The Kroeker empirical equation could be used in various forms and we decided to rewrite it in the dimensionally correct way:

$$
\frac{m^{\mathrm{s}}(\mathrm{As})}{m(\mathrm{LDH})}=\frac{\gamma_{0}(\mathrm{As})}{\gamma(\mathrm{LDH})}\left(1-e^{-k \gamma(\mathrm{LDH})}\right)
$$

where $m^{\mathrm{s}}$ (As) presents the mass of adsorbed substance, $m(\mathrm{LDH})$ states for the mass of adsorbent (here LDH), $\gamma_{0}(\mathrm{As})$ is the initial mass concentration of the adsorbed substance, $\gamma(\mathrm{LDH})$ is the adsorbent mass concentration and $k$ is an empirical constant. The Kroeker equation could generally be used for investigating the adsorption of solutes (e.g. adsorption of color molecules in the textile industry) for the purpose of possible technical application. Therefore, the above equation, as an empirical formula, could be used to describe the water cleaning processes since it is important to know a relevant amount of LDH needed for such a process.

\section{Control of Analytical Procedure}

HG-ICP-AES measurements of arsenic lines in dualview mode showed that the detection power is greater in axially viewed configuration than radial. Detection limits ( $3 \sigma$ criterion, $n=11$, matrix matched solution) of 
arsenic lines at $189.042 \mathrm{~nm}$ and $193.759 \mathrm{~nm}$ in axial view gave $0.003 \mathrm{mg} \mathrm{dm}^{-3}$ and $0.002 \mathrm{mg} \mathrm{dm}^{-3}$, respectively. The precision of intensity measurements on chosen analytical emission lines comprises $0.1-1.0 \%$ RSD. Good linearity of standard calibration curves on both observed lines was obtained $\left(R^{2}=0.9999\right)$. Intensity measurement in MSA mode showed that linear coefficients comprised the same values $\left(R^{2}=0.9996\right)$ at both observed lines.

The accuracy of procedure was tested by certified reference material of river water (SLRS-4, NRCC) with declared arsenic content of $0.68 \pm 0.06 \mu \mathrm{g} \mathrm{dm}^{-3}$. Arsenic content in reference sample which was measured after hydride generation from hydrochloric acidified solution has yield $0.71 \pm 0.02 \mu \mathrm{g} \mathrm{dm}^{-3}$. The obtained result was in very good agreement with certified value (Recovery $104.4 \%)$.

In the first step of our study we performed the experiments using groundwater samples and later on we used model arsenic solutions in order to compare these two systems.

\section{Adsorption of Arsenic from Groundwater}

Adsorption of arsenic from groundwater samples on $\mathrm{MgAl}$ layered double hydroxide was investigated on the example of the samples obtained from 4 different wells around Osijek (noted as B2, B8, B10 and B13). For that purpose we initially determined the mass concentration of arsenic in groundwater samples and then performed the adsorption experiments using these samples by varying the substrate (i.e. LDH) mass concentration. The arsenic concentrations in the 4 investigated samples were $\gamma(\mathrm{B} 2)=0.300 \mathrm{mg} \mathrm{dm}^{-3}, \gamma(\mathrm{B} 8)=0.18 \mathrm{mg} \mathrm{dm}^{-3}$, $\gamma(\mathrm{B} 10)=0.069 \mathrm{mg} \mathrm{dm}^{-3} \gamma(\mathrm{B} 13)=0.195 \mathrm{mg} \mathrm{dm}^{-3}$.

The results are presented in Figure 3. and it could be concluded that all the examined groundwater samples behave as expected according to the Kroeker isotherm.
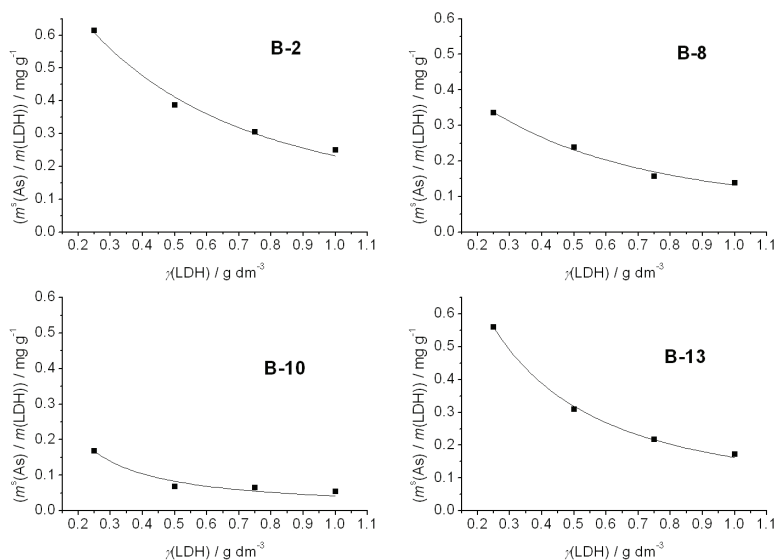

Figure 3. Kroeker isotherm for adsorption of groundwater samples on $\mathrm{MgAl}$ LDHs with molar ratio $\mathrm{NO}_{3}{ }^{-} / \mathrm{CO}_{3}{ }^{2-}$ of 0.1 . The lines are fitted according to Kroeker isotherm (Eq. 2).
This means that the value of the term presented on the ordinate decreases with the increase in adsorbent concentration and it should continue decreasing until the zero value is reached.

\section{Adsorption of the Model Arsenic Sample}

In the second step of our study we investigated the so called model arsenic solution. By model arsenic solution we mean the solution obtained by dissolving commercially obtained arsenic in water. In order to do that the experiments were performed using 3 different initial concentrations of arsenic expressed in mass of As per $\mathrm{dm}^{3}$ and 4 different substrate (i.e. LDH) mass concentrations. The results are presented in Figure 4 and the typical shape of the Kroeker adsorption isotherm, Eq. (2), was obtained again.

The adsorption data interpreted according to Kroeker isotherm could give valuable information about the parameters that define the examined system arsenic/LDH. As observed in Figure 3. for adsorption of arsenic from groundwater and in Figure 4. for adsorption of arsenic from model solution the adsorbed amount of arsenic (precisely the mass of adsorbed arsenic per the mass of LDH) at constant initial arsenic concentration decreases with the increase in LDH mass concentration and that decrease could be extrapolated to zero at infinitely large amounts of LDH.

The experimentally obtained data enabled us to further analyze the Kroeker isotherm. The constant $k$ from Eq. (2) could be expressed as

$$
k=-\frac{\ln \left(1-\frac{m^{\mathrm{s}}(\mathrm{As})}{m(L D H)} \frac{\gamma(\mathrm{LDH})}{\gamma_{0}(\mathrm{As})}\right)}{\gamma(\mathrm{LDH})}
$$

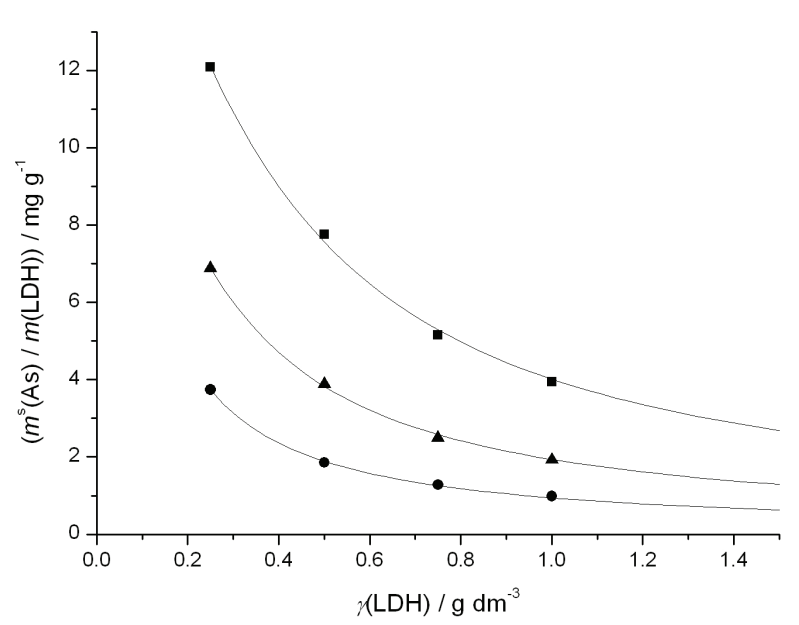

Figure 4. Kroeker adsorption isotherms for adsorption of arsenic on $\mathrm{MgAl} \mathrm{LDHs}$ with molar ratio $\mathrm{NO}_{3}{ }^{-} / \mathrm{CO}_{3}{ }^{2-}$ of 0.1 , from $\mathrm{NaCl}$ aqueous solution $\left(c=0.02 \mathrm{~mol} \mathrm{dm}^{-3}\right)$. Initial arsenic concentrations: $1 \mathrm{mg} \mathrm{dm}^{-3}(\bullet), 2 \mathrm{mg} \mathrm{dm}^{-3}(\mathbf{\Lambda}), 4 \mathrm{mg} \mathrm{dm}^{-3}(\mathbf{\bullet})$. The lines are fitted according to Kroeker isotherm, Eq. (2). 
From the Eq. (3) the Kroeker empirical constant $k$ was determined $6.0 \pm 0.5 \mathrm{dm}^{3} \mathrm{~g}^{-1}$. It seems that the mentioned constant $k$ does not depend strongly on the initial concentration of adsorbent, but, on the other hand, it depends on the specific surface area and on the maximum adsorbed amount.

In the next step we tried to interpret the obtained results by means of Langmuir isotherm. Some authors ${ }^{27,28}$ claim that the classical Langmuir equation cannot describe the adsorbent concentration effect. The reason therefore is the fact that the basic assumptions of classical Langmuir equation are not easily met under real experimental conditions since the deviation of a real adsorption system from an ideal one was not accounted in the derivation process of the classical Langmuir equation. Nevertheless, we tried to interpret our results by classical Langmuir isotherm. Since the mutual interactions could not be excluded, the obtained fit was rather poor $\left(R^{2}=\right.$ 0.73 ) and the Langmuir parameters could be just roughly estimated to be $\Gamma_{\max } \approx 2 \cdot 10^{-6} \mathrm{~mol} \mathrm{~m}^{-2}$ (which corresponds to $\approx 7 \mathrm{mg} \mathrm{g}^{-1}$ ) and $K \approx 2 \cdot 10^{-6} \mathrm{~m}^{2} \mathrm{dm}^{-3}$.

\section{The Influence of Phosphate on Arsenic Adsorption}

The main difference between model arsenic solution and groundwater samples is the presence of additional compounds in groundwater samples. Therefore, we added various amounts of phosphate into the pure arsenic solution in order to "mimic" the groundwater sample. In that way we could examine the possible influence of phosphate, which is present in the investigated groundwater samples, on the adsorption of arsenic. The investigation was performed in the arsenic concentration range between $0.5 \mathrm{mg} \mathrm{dm}^{-3}$ and $4 \mu \mathrm{g} \mathrm{dm}^{-3}$ and in phosphate concentration range between $0.05 \mathrm{mg} \mathrm{dm}^{-3}$ and 2 $\mathrm{mg} \mathrm{dm}^{-3}$. The choice of the phosphate concentration was determined by fact that in the investigated groundwater the phosphate concentration was found to be the range between $0.05 \mathrm{mg} \mathrm{dm}^{-3}$ and $0.1 \mathrm{mg} \mathrm{dm}^{-3}$ so therefore we decided to use these and somewhat higher values. The experiments were carried out twice and the results are shown in Figure 5. as the function of mass concentration of added phosphate in order to determine the possible effect of phosphate concentration on adsorbed amount of arsenic.

From the results presented in Figure 5. it could be concluded that (at least in examined range of arsenic and phosphate concentrations) there is no significant influence of phosphate on the adsorption process. It is known that the competition between arsenate and phosphate ions could be influenced by e.g. $\mathrm{pH}$, reaction time, surface coverage and, last but not least, sequence of addition of the anions. ${ }^{29,30}$ Violante and coworkers ${ }^{29}$ showed that the final arsenate adsorbed/phosphate adsorbed molar ratio increased by adding arsenate before phosphate, but decreased by adding phosphate before
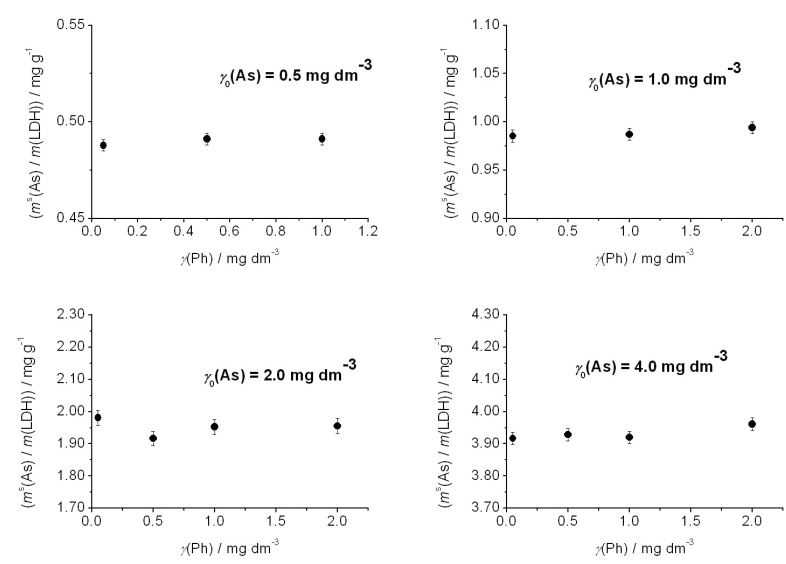

Figure 5. Adsorbed amount of arsenic on $\mathrm{MgAl} \mathrm{LDHs}$ with molar ratio $\mathrm{NO}_{3}^{-} / \mathrm{CO}_{3}{ }^{2-}$ of 0.1 as a function of the concentration of added phosphate for four different initial arsenic concentrations. Average values for two measurements are presented with corresponding error bars.

arsenate. Since in our experiments phosphate was always added into arsenate solution it is not surprising the influence of phosphate on arsenate adsorption is not large.

\section{CONCLUSION}

From the results presented in our study it could be concluded that MgAl LDH is a suitable substrate for arsenic adsorption. The experimentally obtained adsorption data were interpreted according to the Kroeker isotherm and it was shown that that isotherm could be used for arsenic/MgAl LDH aqueous interface. The comparison of the results obtained using model and groundwater samples shows that Kroeker isotherm could be used in both cases. Moreover, at least as phosphate is concerned, there is no significant effect of additional compounds presented in groundwater on arsenic adsorption. The results obtained in our study could be useful also in further studies of arsenic adsorption and even present a baseline for possible applications of such systems for removal of arsenic from groundwater.

Acknowledgements. This research was supported by the NATO Collaborative Linkage Grant CLG No. 983776 and by the COST Action CM1101. The authors are grateful to Željka Romić and Zoran Velagić for their assistance with groundwater samples.

\section{REFERENCES}

1. Guidelines for Drinking Water Quality, Vol. 1, Recommendations, $3^{\text {rd }}$ edition, World Health Organization, Geneva, 2008.

2. P. L. Smedley and D. G. Kinniburgh, Appl. Geochem. 17 (2002) 517-568.

3. P. L. Smedley, H. B. Nicolli, D. M. J. Macdonald, A. J. Barros, and J. O. Tullio, Appl. Geochem. 17 (2002) 259-284. 
4. M. L. Polizzotto, C. F. Harvey, G. Li, B. Badruzzman, A. Ashraf, M. Newville, S. Sutton, and S. Fendorf, Chem. Geol. 228 (2006) 97-111.

5. M. E. Gutiérrez-Ruiz, A. E. Ceniceros-Gómez, M. Villalobos, F. Romero, and P. Santiago, Appl. Geochem. 27 (2012) 2004-2014.

6. C. Luengo, M. Brigante, and M. Avena, J. Colloid Interf. Sci. 311 (2007) 354-360.

7. M. Habuda-Stanić, M. Kuleš, B. Kalajdžić, and Ž. Romić, Desalination 210 (2007) 157-162.

8. S. Ćavar, T. Klapec, R. Jurišić Grubešić, and M. Valek, Sci. Total Envir. 277 (2005) 277-282.

9. I. Varsányi and L. Ó. Kovács, Appl. Geochem. 21 (2006) 949-963.

10. S. Bang, M. D. Johnson, G. P. Korfiatis, and X. Meng, Water Res. 39 (2005) 763-770.

11. J. Farrel, J. P. Wang, P. O. Day, and M. Conklin, Environ. Sci. Technol. 35 (2001) 2026-2032.

12. V. Rives and M. A. Ulibarri, Coordin. Chem. Rev. 181 (1999) 61-120.

13. A. I. Khan and D. O'Hare, J. Mater. Chem. 12 (2002) 31913198.

14. I. Dékány, F. Berger, K. Imrik, and G. Lagaly, Colloid Polym Sci. 275 (1997) 681-688.

15. H. Kopka, K. Beneke, and G. Lagaly, J. Colloid Interf. Sci. 123 (1988) 427-436.

16. V. Hornok, A. Erdőhelyi, and I. Dékány, Colloid Polym. Sci. $\mathbf{2 8 3}$ (2005) 1050-1055.
17. T. Aradi, V. Hornok, and I. Dékány, 2007. Colloids Surf. A. 319 (2007) 116-121.

18. A. I. Tsyganok, T. Tsunoda, S. Hamakawa, K Suzuki, K. Takehira, and T. Hayakawa, J. Catal. 213 (2003) 191-203.

19. J-H. Choy, S-J. Choi, J-M. Oh, and T. Park, Appl. Clay Sci. 36 (2007) 122-132.

20. S. Bhattacharjee, T. J. Dines, and A. A. James, J. Catal. 225 (2004) 398-407.

21. S. Aisawa, Y. Ohnuma, K. Hirose, S. Takahashi, H. Hirahara, and E. Narita, Appl. Clay Sci. 28 (2005) 137-145.

22. Q. Z. Yang, J. Yang, and C. K. Zhang, Int. J. Pharm. 326 (2006) $148-152$.

23. D. G. Kinniburgh, Environ. Sci. Technol. 20 (1986) 895-904.

24. D. Kovačević, N. Kallay, I. Antol, A. Pohlmeier, H. Lewandovski, and H.-D. Narres, Colloids Surf. A 140 (1998) 261-267.

25. E. A. Hauser, Colloidal Phenomena - an Introduction to the Science of Colloids, McGraw-Hill, New York and London, 1939.

26. P. Mehl, Kolloid-Zeitschrift 56 (1931) 299-305.

27. L.-X. Zhao, S.-E. Song, N. Du, and W.-G. Hou, Colloid Polym. Sci. 291 (2013) 541-550.

28. L.-X. Zhao, S.-E. Song, N. Du, and W.-G. Hou, Acta Phys.Chim. Sin. 28 (2012) 2905-2910.

29. A. Violante, M. Pucci, V. Cozzolino, J. Zhua, M. Pigna, J. Colloid Interf. Sci. 333 (2009) 63-70.

30. A. G. Caporale, M. Pigna, J. J. Dynes, V. Cozzolino, J. Zhu, and A. Violante, J. Hazard. Mater. 198 (2011) 291-298. 